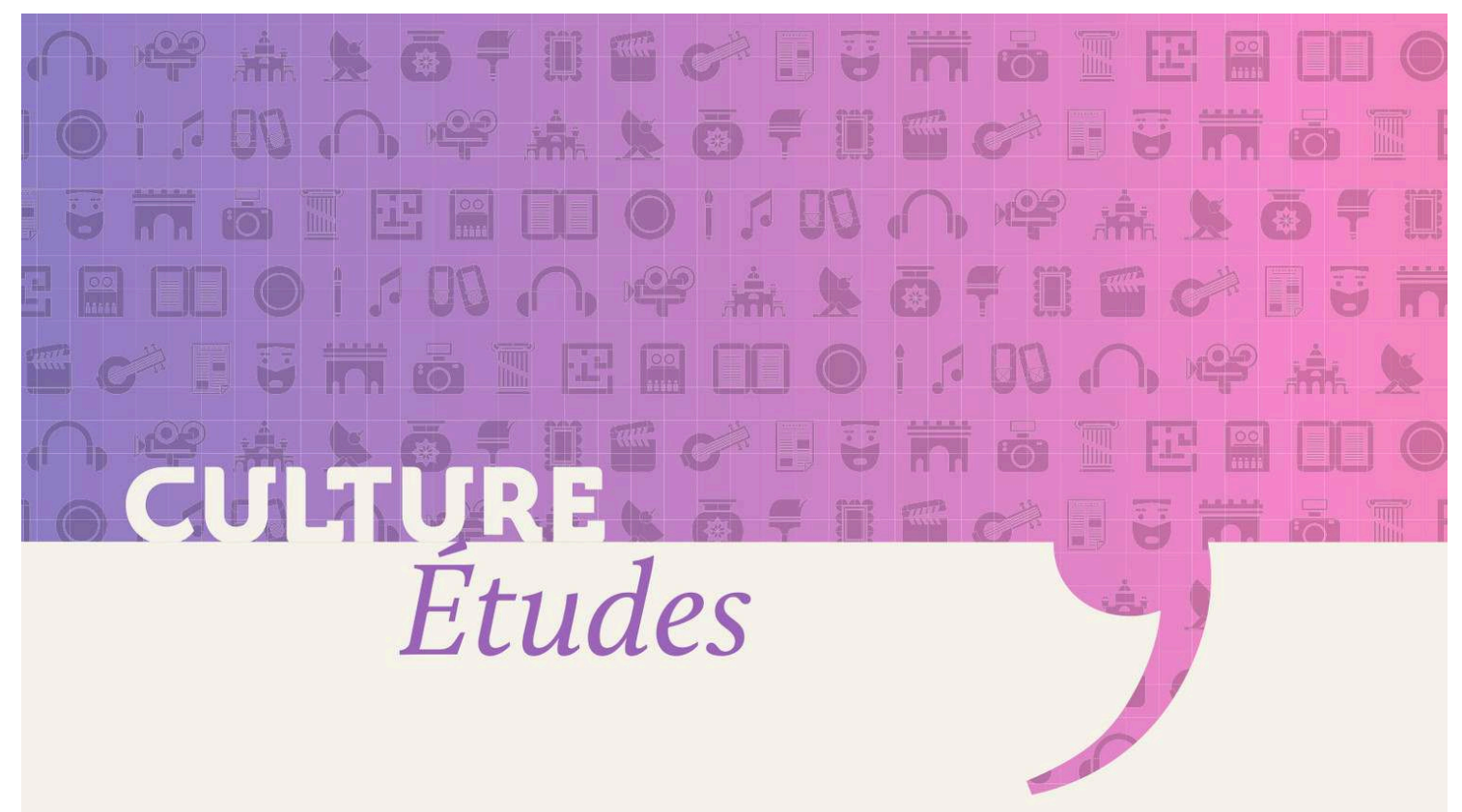

\title{
Les représentations de la culture dans la population française
}

\author{
Jean-Michel Guy
}
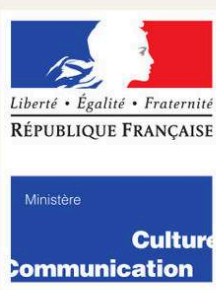

2016-1

Ministère de la Culture et de la Communication Département des études, de la prospective et des statistiques 


\section{Les représentations de la culture dans la population française}

Representations of Culture in the French Population

Jean-Michel Guy

Éditeur : Département des études, de la prospective et des statistiques

Lieu d'édition : Paris

Année d'édition : 2016

Date de mise en ligne : 23 février 2018

Collection : Culture études

ISBN électronique : 9782111399457

\section{Sobooks}

http://books.openedition.org

Édition imprimée

Nombre de pages : 18

Référence électronique

GUY, Jean-Michel. Les représentations de la culture dans la population française. Nouvelle édition [en ligne]. Paris : Département des études, de la prospective et des statistiques, 2016 (généré le 25 avril 2021). Disponible sur Internet : <http://books.openedition.org/deps/1199>. ISBN : 9782111399457. 


\title{
GणnTDF Etudes
}

\section{Les représentations de la culture dans} la population française

\author{
Jean-Michel Guy
}

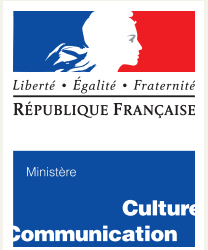

2016-1

Ministère de la Culture et de la Communication Département des études, de la prospective et des statistiques 


\title{
Les représentations de la culture dans la population française
}

\author{
Jean-Michel Guy*
}

Que recouvre le terme de « culture » dans l'esprit des Français, quelles sont les représentations spontanées qui lui sont associées et à quels registres renvoientelles ? Pour le savoir, et dans la perspective de la reconduite de l'enquête décennale sur les pratiques culturelles des Français réalisée depuis 1970 par le ministère de la Culture et de la Communication, le Département des études, de la prospective et des statistiques a mené, auprès d'un échantillon de 1500 personnes représentatives de la population française, une étude sur les représentations et les valeurs associées à la culture.

Les évocations spontanées de mots et expressions pour référer à la culture peuvent être regroupées, selon leur proximité sémantique, en 28 registres. Le premier d'entre eux, mobilisé par $41 \%$ des Français, fait référence au savoir et à la connaissance, le deuxième à la littérature et à la lecture et le troisième à la musique et à la danse. Si l'on observe un consensus autour du patrimoine et des arts, mais aussi des voyages, de la science et de la cuisine comme faisant partie de la culture dans tous les cas, des lignes communes de rejet se dessinent également, excluant du champ culturel les émissions de téléréalité et les séries télévisées, les jeux vidéo ou les parcs d'attractions.

Quatre grands types de conception de la culture se dégagent : le libéralisme culturel (tout est culturel), l'éclectisme critique (tout est potentiellement culturel, selon certains critères), le classicisme (le champ culturel n'est pas extensible) et l'attitude contestataire (la vraie culture est ailleurs).

Si les jeunes (15-24 ans) incluent volontiers dans la culture des modes d'expression et des formes de culture médiatique, et les femmes un plus grand nombre de contenus et d'activités que les hommes, on observe globalement une faible influence des variables qui déterminent historiquement la participation culturelle, en particulier l'origine sociale. Tout se passe comme si une représentation commune de la culture assez extensive s'était imposée et traversait tous les groupes sociaux.

* Chargé d'études au Département des études, de la perspective et des statistiques, ministère de la Culture et de la Communication. 
Quelles réalités le mot «culture » recouvre-t-il dans l'esprit de nos concitoyens ? De la définition héritée des beaux-arts à une vision beaucoup plus large intégrant le graffiti, les jeux vidéo, la mode ou encore l'industrie du luxe, le spectre du champ culturel est à géométrie variable. Une définition commune en a été proposée au niveau européen pour délimiter ce qu'il est possible de mesurer statistiquement dans l'ensemble des pays de l'Union européenne, mais qu'en est-il de la définition spontanée qu'en donnent les Français ?

Si les éditions successives de l'enquête décennale sur les pratiques culturelles des Français, conduites régulièrement depuis les années 1970, permettent de mesurer, et en partie d'expliquer l'inégale diffusion de la participation culturelle au sein de la population, elles laissent néanmoins entière la question du sens que les Français attribuent aux activités culturelles, qu'ils les pratiquent, plus ou moins intensément, ou non.

Dans la perspective du renouvellement de l'enquête sur les pratiques culturelles, l'étude sur les représentations de la culture et les valeurs qui leur sont associées vient enrichir la compréhension du rapport que les Français entretiennent avec la culture.

\section{Polysémie du mot « culture »}

Lorsqu'on leur demande ce que le terme de "culture » évoque spontanément pour eux, les Français ont presque toujours une réponse à donner. L'enquête sur les représentations et valeurs associées à la culture débute, en effet, par des questions ouvertes qui permettent aux personnes interrogées de s'exprimer spontanément sur ce que recouvre, selon eux, ce vocable (voir Éléments de méthodologie, p. 15). Premier résultat à souligner : extrêmement rares sont les personnes incapables de citer quoi que ce soit, puisque $99 \%$ des personnes ont une réponse à donner, qu'il s'agisse de genres artistiques, de lieux ou d'une tentative de définition. Ces réponses comportent par ailleurs très rarement ( $1 \%$ des cas seulement) des adjectifs ou des expressions

\section{Graphique 1 - Évocations spontanées du mot « culture »}

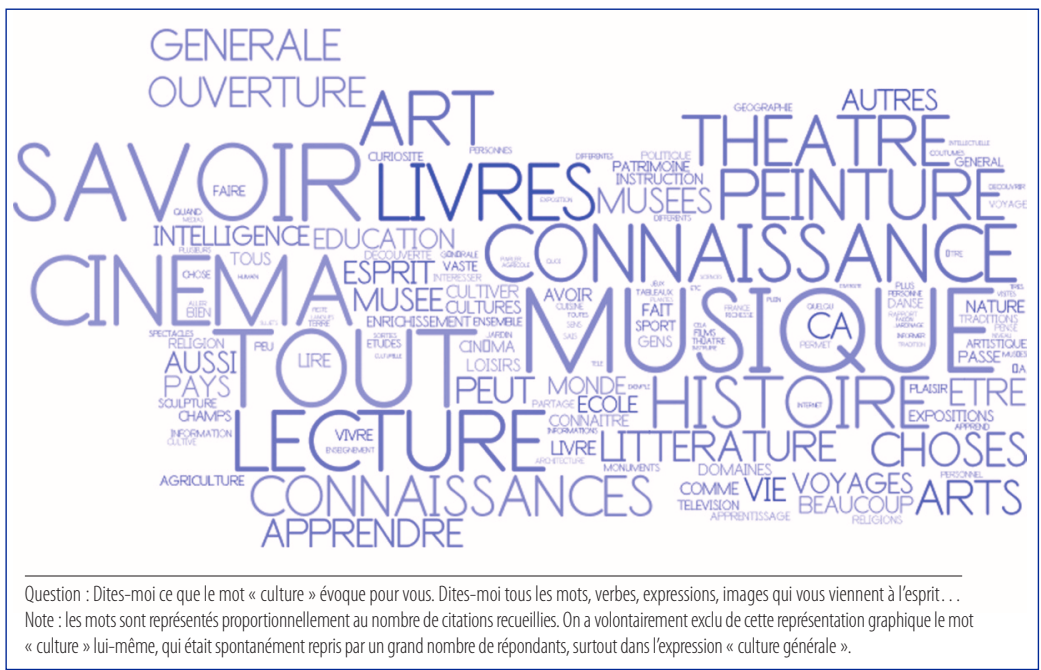

Source : Crédoc/DEPS, Ministère de la Culture et de la Communication, 2016 
exprimant un jugement négatif (" élitiste », «bourrage de crâne ») : le mot " culture » évoque spontanément à chacun un ou plusieurs registres de réponses, dénuées de jugement de valeur, et les registres s'entrecroisent de façon complexe.

\section{La culture comme somme de savoirs et de connaissances}

Premier constat, le mot « culture » dans la bouche des Français se caractérise par sa polysémie. Le vaste ensemble de mots et expressions spontanément mobilisés pour évoquer la culture peut être ramené à 28 registres, regroupant les termes utilisés selon leur proximité sémantique et cognitive (graphique 1). Le premier de ces registres concerne celui du savoir et de la connaissance, spontanément mobilisé par $41 \%$ des Français pour évoquer la culture (graphique 2). Très courant dans les réponses données, ce registre renvoie à une conception héritée de la vision encyclopédique du siècle des Lumières : la culture comme somme de savoirs, accumulés et transmis, ou comme

\section{Graphique 2 - Évocations spontanées du mot « culture » regroupées en 28 registres}

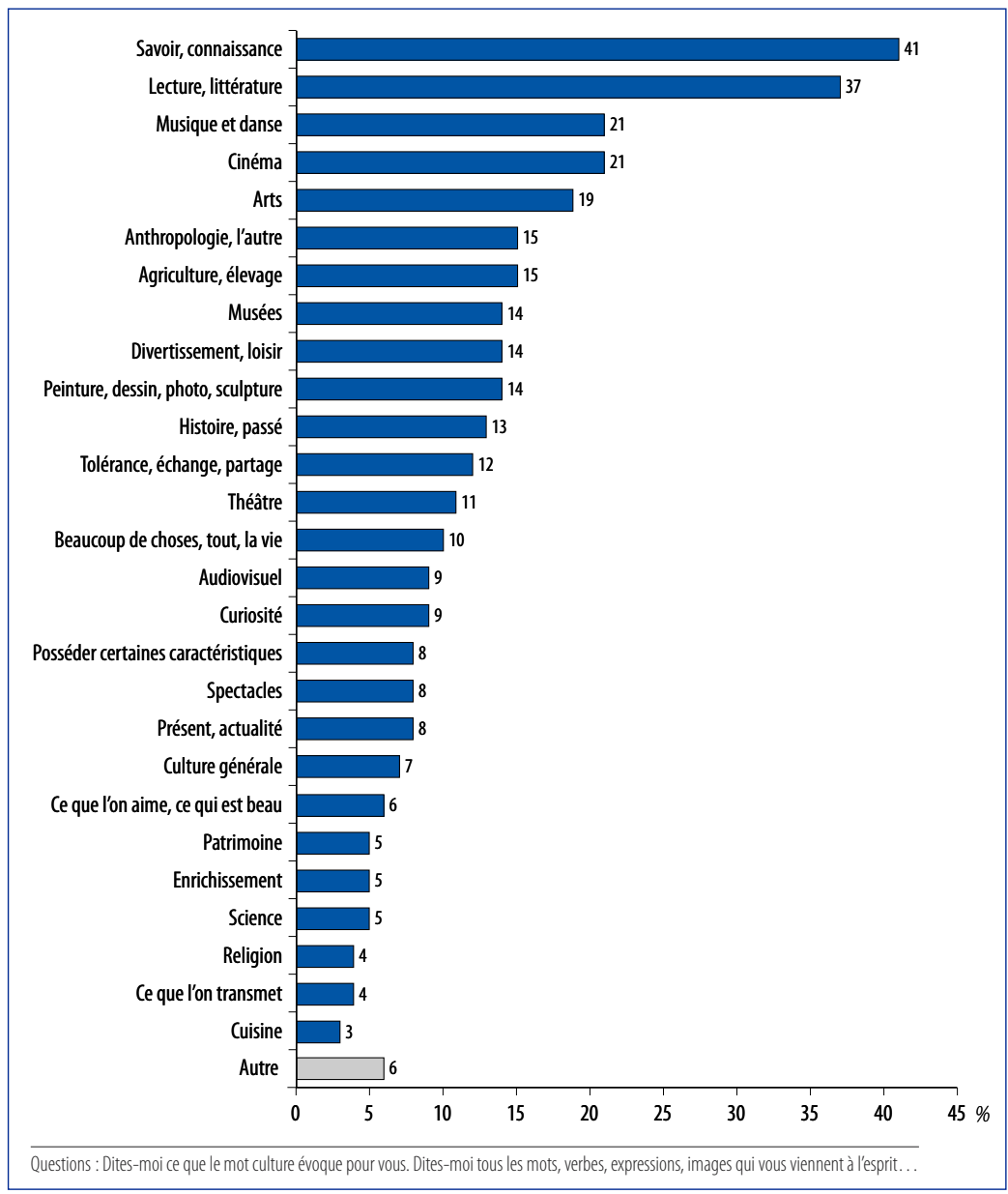


processus d'acquisition de connaissances et d'apprentissage. Les réponses mobilisent souvent des termes relatifs à la lecture et à la littérature : désignant aussi bien la pratique («la lecture », « lire »), l'objet (« les livres »), le domaine d'expression (« la littérature »), que les lieux («bibliothèques»), ce registre est évoqué par plus d'un tiers des Français (37\%) et manifeste le rôle particulièrement prégnant du livre comme socle symbolique de la culture dans leurs représentations. Viennent ensuite une série de registres pointant chacun divers domaines de l'expression artistique : la musique et la danse (21\%), le cinéma (21\%) ainsi que les arts, sans autre précision (19\%).

\section{La culture comme ensemble d'us, coutumes et valeurs d'un même groupe humain}

Regroupant dans cette catégorie les vocables évoquant des pratiques vestimentaires, alimentaires, ethniques, le pluriel « les cultures», les mœurs, les religions, ou la question « des autres », un registre que nous qualifions d'anthropologique est spontanément cité par un Français sur huit.

\section{Des lieux de culture et des pratiques}

Enfin, le registre des lieux culturels (musées, maisons de la culture, centres culturels) est mobilisé par $14 \%$ des répondants. Dans une catégorie proche, $5 \%$ des répondants ont évoqué le patrimoine bâti (« les monuments», « les châteaux», etc.).

Pour $14 \%$ des répondants, la culture est associée à un divertissement ou une pratique de loisirs. D'autres contenus sont évoqués avec des scores voisins, qui désignent à la fois une discipline artistique et des pratiques en amateur : la peinture, le dessin ou la sculpture (14\%), ou encore le théâtre (11\%).

\section{Un sens plus terrien du mot " culture "}

Enfin, un registre très différent revient malgré tout dans une citation sur huit : il s'agit des termes se rapportant à l'agriculture (dont ce mot lui-même), à l'élevage et aux différentes productions possibles de biens agricoles, et donc des références au sens premier du terme « culture».

Chez un répondant sur dix, le mot «culture » est aussi associé spontanément à certaines valeurs comme la tolérance, l'ouverture et le partage (12\%) ou encore à la curiosité (9\%). Enfin, notons que pour une personne sur dix, la culture est présentée comme vaste, complexe, incluant tous les domaines et reflétant tous les possibles de la vie, symbole de l'humanité (10\%) : la culture, c'est « tout». Les autres évocations recueillent chacune moins de $10 \%$ des réponses.

\section{Graphique 3 - Évocations spontanées du mot « culture » regroupées en cinq grands registres}

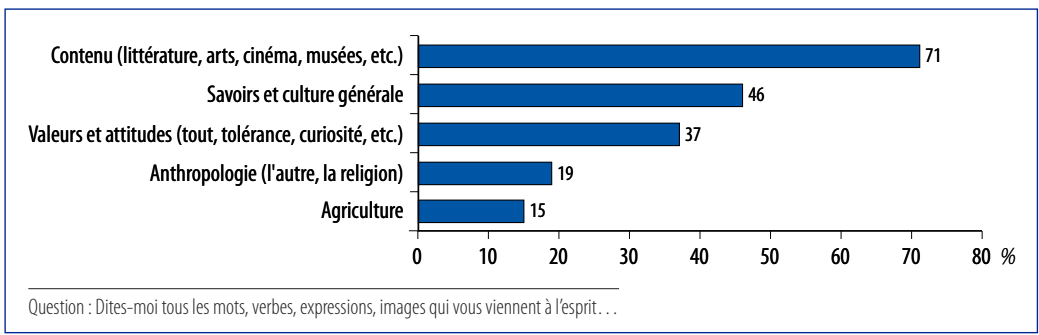

Source : Crédoc/DEPS, Ministère de la Culture et de la Communication, 2016 


\section{Arts, savoirs, valeurs, anthropologie, agriculture : les cinq acceptions spontanées de la culture}

L'ensemble de ces registres dessine un espace d'autant plus complexe que les répondants en mobilisent souvent plusieurs pour exprimer ce que la culture évoque. Le choix a été fait de regrouper ces registres en cinq grands ensembles qui dessinent les contours des acceptions spontanées de ce terme (graphique 3 ) :

- un premier registre repose sur l'association de la culture avec une discipline artistique (la littérature, le cinéma, la peinture, la sculpture, le théâtre, les spectacles, etc.) ou des équipements culturels (musées, monuments, bibliothèques, etc.), et l'audiovisuel. C'est, de loin, le registre le plus fréquemment mobilisé : $71 \%$ des répondants y font spontanément référence ;

- le deuxième registre associe la culture à la connaissance, au savoir, à la culture générale. Près d'une personne sur deux (46\%) fait cette association ;

- un troisième registre assimile la culture à des valeurs comme la tolérance, le bien-être, la curiosité, l'enrichissement, ou la présente sous un angle global (" c'est la vie », «c'est tout »...) : $37 \%$ des répondants souscrivent à cette vision ; - un quatrième registre fait référence à une définition anthropologique : la culture désigne ce qui caractérise la façon de vivre ou de penser d'un groupe d'individus, ou encore c'est l'autre, celui qui n'a pas la même religion ou la même langue. $19 \%$ des répondants évoquent ce registre ;

- enfin, un cinquième registre assimile la culture à l'agriculture : $15 \%$ des répondants font spontanément cette association.

Deux Français sur trois définissent la culture par au moins deux de ces registres, et les associations entre les registres sont innombrables: leur combinaison est très variable d'une personne à l'autre. La combinaison la plus fréquente est celle qui associe au moins une discipline artistique ou un équipement culturel au savoir ( $24 \%$ des combinaisons).

\section{Ce qui fait et ce qui ne fait pas culture}

Au-delà des premières évocations spontanées que suscitait le terme de « culture », l'enquête soumettait ensuite aux répondants une liste d'activités (lire des romans, par exemple) ou domaines (la science, la mode, le cirque...), dont ils devaient dire s'ils entraient, selon eux, dans le périmètre de la culture. II s'agissait moins de reconstituer le champ culturel des individus, dont on peut supposer qu'il inclut potentiellement bien plus que 27 activités ou domaines, que de dessiner les contours des différents univers culturels symboliques des Français. On ne s'étonnera donc pas de ne pas voir figurer dans la liste des domaines ou des activités comme l'archéologie, les fêtes foraines, le jazz, l'opéra, l'urbanisme, les marionnettes, le rock, la danse contemporaine, la musique militaire ou encore la corrida. L'objectif était d'identifier tout à la fois d'éventuels consensus sur un périmètre minimal, et des désaccords significatifs.

L'un des résultats les plus remarquables est la faible influence des variables sociodémographiques sur les réponses, ou, en d'autres termes, la relative faiblesse des écarts entre catégories d'âge, de revenus, de niveau de diplôme, de catégorie socioprofessionnelle ou de lieu d'habitation. Si quelques écarts, présentés plus loin, sont significatifs, il se dégage une forme de consensus social sur le périmètre de la culture. Examinons donc d'abord les représentations communes, partagées par des Français de conditions sociales très diverses. 


\section{Un consensus social autour du patrimoine et des arts...}

Pour une personne interrogée sur deux au moins, une dizaine d'activités sont considérées comme faisant partie de la culture dans tous les cas, par ordre décroissant de fréquence de citation : la visite de musées ou de monuments (84\%), la science (77\%), les voyages (73\%), la cuisine (62 \%), aller au théâtre (62\%), lire la presse (58\%), écouter de la musique classique (57\%), lire des romans (57\%), jouer d'un instrument de musique ( $53 \%$ ) et aller au cinéma (50\%) (graphique 4).

Cette première liste fait apparaître la très haute estime dont jouissent la science, les voyages ainsi que la cuisine, placée au même niveau que le théâtre et devançant, par exemple, l'écoute de musique classique ou la pratique d'un instrument de musique. Que la visite de lieux de patrimoine fasse partie de la culture pour une écrasante majorité n'est guère pour surprendre. En revanche, la place de la science, des voyages et de la cuisine est d'autant plus remarquable que ces trois mots n'ont pas ou guère été cités en réponse à la question ouverte, précédemment évoquée. Certes, considérer la science comme faisant partie de la culture est cohérent avec la représentation dominante de la culture comme connaissance, ou comme somme de savoirs. Ce score de la science suggère même que la culture comporterait en son sein un noyau sacré, inaccessible sans initiation.

\section{... mais aussi des voyages, de la science et de la cuisine}

L'inclusion des voyages dans le périmètre de la culture n'est probablement pas sans lien avec l'attachement au patrimoine muséal et monumental, comme le rappelle le titre d'une émission fort prisée des téléspectateurs, Des racines et des ailes. Les voyages évoquent la curiosité, la découverte et le partage, des valeurs souvent associées à la culture, et il est peu probable que les répondants aient compris l'expression «les voyages » comme simple synonyme de mobilité. Ce que l'on découvre dans un voyage réel, touristique ou non, ou dans un voyage par procuration, par l'intermédiaire d'un programme de télévision par exemple, ce serait forcément quelque chose d'inédit, de potentiellement surprenant et d'enrichissant. La culture est ainsi associée à un déplacement du cadre de référence, à la découverte de territoires géographiques et symboliques inconnus.

La faveur dont jouit ici la cuisine est sans doute à mettre en relation avec l'inscription récente par l'Unesco du repas gastronomique des Français sur la liste du patrimoine immatériel de l'humanité et, plus particulièrement encore, avec la multiplication des émissions de télévision consacrées à la cuisine (Top chef, etc.). Elle est liée aussi à l'importance que les Français accordent à la cuisine comme élément constitutif de la culture française (33\% estiment que c'est un élément indispensable et $50 \%$ que c'est un élément important pour définir la culture française) et qu'ils reconnaissent également comme participant de la culture «des autres » : $80 \%$ des Français aiment les cuisines étrangères (75\% en milieu rural et $90 \%$ dans l'agglomération parisienne). On note ici que l'extrême hétérogénéité de la cuisine, qui peut aller de la haute gastronomie à la préparation rapide, aurait pu inciter un grand nombre de répondants à ne la considérer comme faisant partie de la culture que dans certains cas, mais une très large majorité $(62 \%)$ désigne pourtant la cuisine comme participant de la culture "dans tous les cas».

Science, cuisine, voyages: même si le ministère de la Culture et de la Communication est loin d'ignorer ces questions (il exerce par exemple une tutelle conjointe avec l'Éducation nationale sur l'établissement public Universciences, voué à la culture scientifique), il faut reconnaître que ces domaines demeurent nettement moins mis en avant que la création, le patrimoine ou les médias. Les médias euxmêmes présentent rarement comme culturelles les émissions consacrées à la science, aux voyages ou à la cuisine : la conception que les Français ont de la culture paraît en 
fait, globalement, plus large que celle qu'en donnent les principales instances de légitimation que sont l'école, les équipements et institutions culturelles et les médias.

\section{Jeux vidéo, parcs d'attractions ou téléréalité unanimement exclus du champ culturel}

Autre élément de consensus, les Français s'accordent sur l'absence de caractère culturel des émissions de téléréalité ( $83 \%)$, des jeux vidéo (63\%), des parcs d'attractions (50 \%) qui, pour une majorité d'entre eux, ne relèvent en aucun cas de la culture. Ils sont près de la moitié, également, à considérer que certaines activités ou certains contenus ne relèvent en aucun cas de la culture, comme aller à la chasse ou à la pêche (48\%), les séries télévisées (46\%), le rap et le hip-hop (44\%), le graffiti et le tag (42\%) ou le fait de danser entre amis (40\%).

\section{Graphique 4 - Appartenance de 27 domaines et activités au périmètre de la culture}

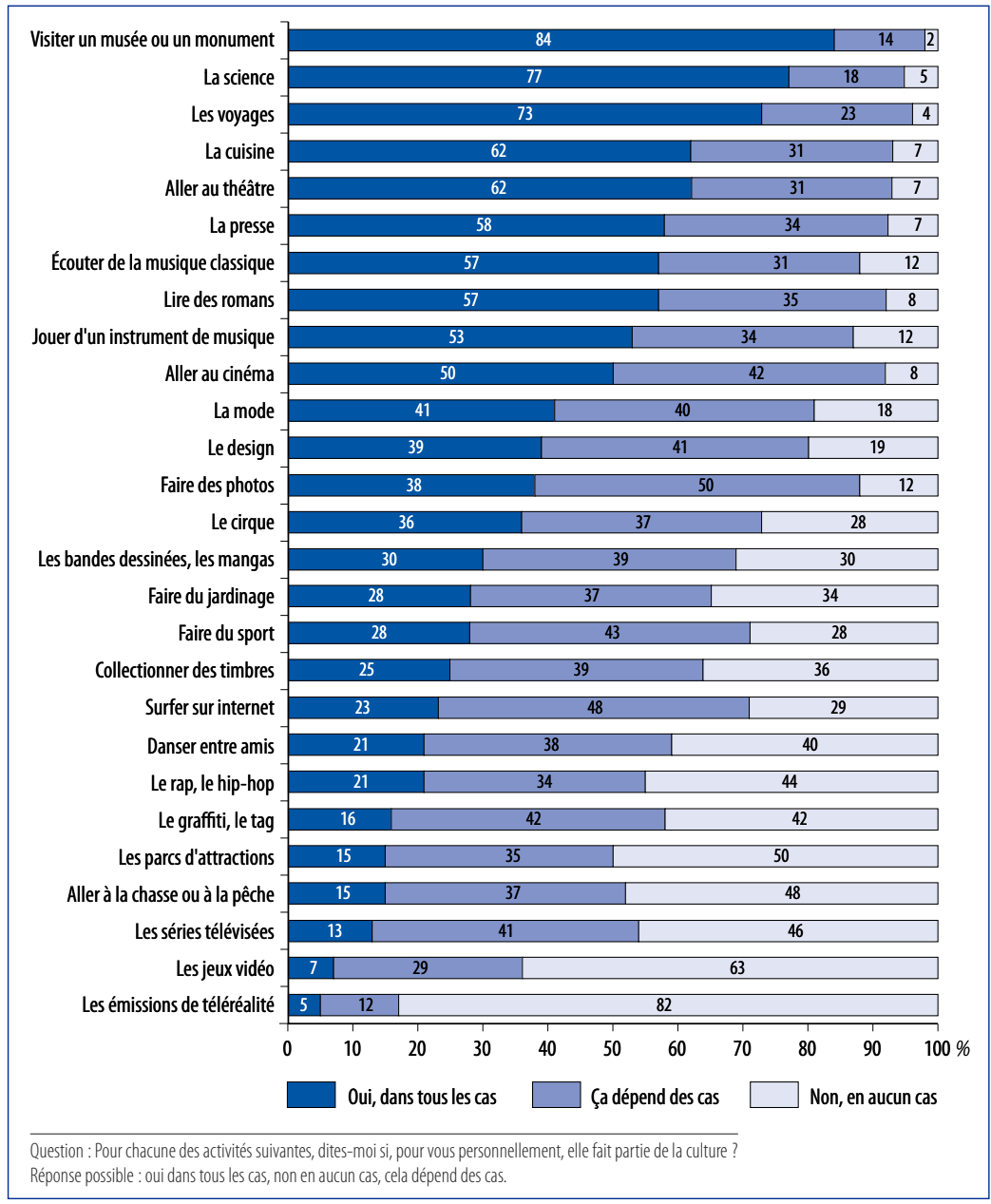


Aucune majorité ne se dégage pour certaines pratiques pour lesquelles les opinions «dans tous les cas» sont aussi nombreuses que les opinions "ça dépend des cas » (la mode, le cirque, le design, par exemple).

\section{Certaines pratiques et domaines ne relèvent de la culture qu'à certaines conditions}

Pour certaines activités et contenus, en revanche, les avis sont conditionnés par différents critères propres à chaque individu, et sans doute fondés sur un système de valeurs plus ou moins partagé. Pour ces activités, la réponse conditionnelle « ça dépend des cas » est très fréquente. Ainsi, faire des photos (50\%), surfer sur internet (48\%), faire du sport (43\%), le design (41\%), les bandes dessinées, les mangas (39\%), collectionner des timbres (38\%), faire du jardinage (37\%), le cirque (36\%) sont-ils, selon les cas, conçus comme culturels ou non. Lorsque cette réponse conditionnelle était donnée pour des activités comme aller au cinéma, lire des romans et de la bande dessinée, les répondants pouvaient préciser leurs critères : le genre de films (71\%) plus que la qualité du film ( $23 \%$ ) apparaît ainsi déterminant, le genre de romans (60\%), plus que sa qualité ( $26 \%)$, le genre de bandes dessinées ou de mangas (51\%). Dans ce dernier cas, la qualité de l'ouvrage (36\%) joue un peu plus sur son intégration ou non dans le champ culturel.

La lecture de ces résultats appelle plusieurs remarques. Nombre d'activités qui, selon les Français, relèvent au moins dans certains cas de la culture n'ont cependant jamais ou guère été spontanément associées au mot "culture » dans la question ouverte : c'est le cas notamment du cirque, des bandes dessinées, des cultures urbaines (rap, hip-hop, graffiti, etc.) ou même de la mode et du design. Elles ne sont pas au cœur des représentations, ne viennent pas spontanément à l'esprit mais leur appartenance à la culture est néanmoins indubitable pour certaines personnes : lorsqu'on leur demande si ces domaines relèvent selon eux de la culture, ils sont par exemple $41 \%$ à l'affirmer pour la mode, $39 \%$ pour le design, $36 \%$ pour le cirque.

Nombre d'activités (visites de musées, théâtre, presse, pratique d'un instrument de musique) sont citées par une part de Français nettement supérieure à celle de leurs pratiquants, que l'enquête décennale sur les pratiques culturelles conduite par le ministère de la Culture et de la Communication permet de mesurer. Il s'agit d'activités plutôt classiques puisque y figurent la pratique d'un instrument de musique, l'écoute de musique classique, la fréquentation de théâtres, la visite de musées ou de monuments. Même des activités comme la chasse et la pêche, que pratiqueraient $4 \%$ à $5 \%$ des Français, sont tenues pour culturelles par une proportion beaucoup plus importante $(15 \%)$.

Inversement, des activités très répandues parmi l'ensemble des Français (comme naviguer sur internet ou jouer à des jeux vidéo) ne sont pas considérées comme relevant de la culture, même par leurs pratiquants les plus assidus. La question des jeux vidéo est à ce titre intéressante : la diversité des contenus, des genres, n'est certainement pas moins grande en ce domaine que celle de la presse ou des romans, et aurait pu justifier une part plus importante de réponses conditionnelles («ça dépend des cas »). En outre, le savoir-faire technique et artistique des concepteurs de jeux vidéo, et le soutien, voire la reconnaissance dont ils jouissent de la part du ministère de la Culture et de la Communication, auraient pu conduire un nombre plus important de personnes à le considérer comme culturel. Or ce n'est pas le cas : le jeu vidéo relève du loisir, de la distraction, voire d'un registre encore moins noble ; très proche, par le score, de la téléréalité, il est loin du sport, qu'un peu plus d'un quart des Français (28\%) considèrent comme faisant partie de la culture dans tous les cas. 


\section{Libéralisme, relativisme critique, classicisme, attitude contestataire : quatre postures vis-à-vis de la culture}

Une analyse multivariée, prenant en compte à la fois les domaines cités comme participant de la culture, leur nombre et le caractère conditionnel de leur appartenance au champ de la culture (" dans tous les cas », "ça dépend des cas », « en aucun cas ») permet d'identifier quatre groupes de répondants, qui ne constituent pas des groupes sociaux homogènes, mais correspondent à des attitudes caractéristiques à l'égard de l'extension du champ de la culture (graphique 5).

\section{Le libéralisme ("Tout est culturel »)}

Ce type rassemble un peu plus du quart (29\%) de la population et se caractérise par une vision très ouverte de la culture : de nombreuses activités la constituent, sans restriction aucune (la modalité « dans tous les cas » est très employée). Dans la question ouverte, les références à des contenus artistiques ou des équipements atteignent ici $76 \%$ (+ 5 points par rapport à la moyenne des réponses). En particulier, la musique (+ 7 points), le cinéma (+ 6 points) ou les livres (+ 5 points) sont souvent évoqués. Ce type est révélateur de l'hybridation de la culture cultivée qui abolit la hiérarchie entre arts majeurs et arts mineurs. Pour les personnes de ce groupe, de nombreuses formes d'expression s'apparentent à de la culture : une personne sur deux y met dans tous les cas le jardinage, le sport ou le rap et le hip-hop.

\section{L'éclectisme critique (" Tout est potentiellement culturel, à certaines conditions ")}

Ce type rassemble près d'un tiers ( $32 \%$ ) de la population et se distingue, comme le précédent, par une vision plutôt ouverte de la culture - toutes les activités proposées y recueillent un taux d'assentiment supérieur à la moyenne -, mais pose toutefois des restrictions ou des conditions (la modalité « ça dépend des cas » est très employée), ce qui pourrait présager un mode d'appropriation critique de certains objets culturels. On constate une légère surreprésentation de la citation des arts $(24 \%,+5$ points par rapport à la moyenne) et de l'histoire (17\%, + 4 points).

Graphique 5 - Nombre d'activités incluses dans le champ de la culture selon les quatre types de posture

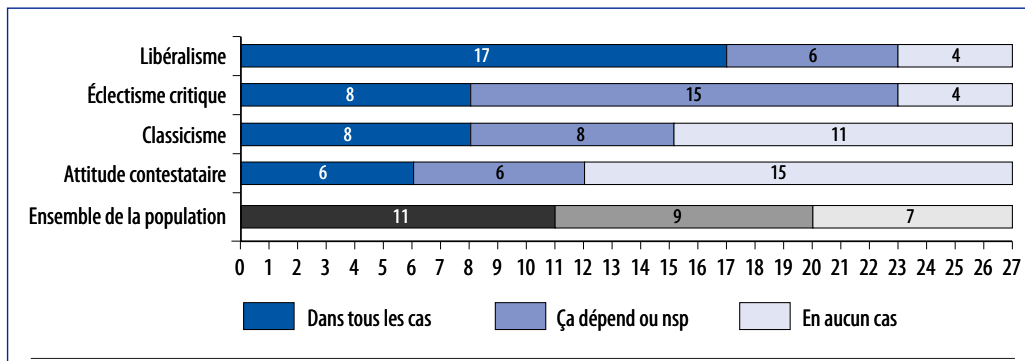

Exemple de lecture : alors que dans l'ensemble de la population, 11 des 27 activités sont majoritairement perçues comme faisant « dans tous les cas » partie de la culture, c'est le cas de 17 activités pour le type « libéralisme » et de 6 seulement pour le type " attitude contestataire ». 


\section{Le classicisme (" La culture n'est pas extensible à l'infini »)}

Ce type rassemble un tiers $(30 \%)$ de la population et restreint la culture à un champ précis, plutôt classique (théâtre, musées, voyages, romans, cinéma...), en excluant fermement les parcs d'attractions, les jeux vidéo, la danse entre amis, les séries télévisées ou le jardinage. Dans ce groupe, la culture est plus souvent associée au savoir, à la connaissance et à la culture générale (pour la moitié des répondants, $50 \%$, contre $41 \%$ dans l'ensemble de la population).

\section{L'attitude contestataire ("La vraie culture est ailleurs ")}

Ce type rassemble $9 \%$ de la population et se distingue par le rejet de toutes les activités proposées : le pourcentage de réponses « ne fait partie de la culture en aucun cas » est systématiquement supérieur au taux moyen. En particulier, on peut noter le choix d'exclure du périmètre de la culture des activités telles que l'écoute de la musique classique (63\%), le théâtre (59\%), le cinéma (53\%), la lecture de romans (53\%).

Or le théâtre et peut-être plus encore la musique classique font figure de piliers de la culture légitime du siècle dernier. Leur mise à l'écart peut s'expliquer par le rejet d'une culture perçue comme appartenant à un autre groupe social que le sien, ou encore par la critique volontaire d'un ordre considéré comme dominant. Dans ce groupe, les réponses à la question ouverte évoquant l'agriculture sont deux fois plus nombreuses qu'en moyenne (32\% contre $15 \%$ en moyenne pour l'ensemble de la population).

\section{Une faible influence de l'origine sociale sur les conceptions de la culture}

Restreindre la culture à un champ aux contours délimités, centré sur le patrimoine et des domaines d'expression artistiques classiques est donc loin d'être une vision communément partagée. Au contraire, l'idée que « tout est potentiellement culturel », soit par principe, soit sous condition de qualité, semble s'être imposée.

En outre, il s'avère difficile de caractériser d'un point de vue sociodémographique les quatre grandes visions de la culture identifiées, car les propriétés sociales des individus composant un groupe se distinguent assez peu d'un groupe à l'autre. Seul le groupe qualifié de " contestataire » manifeste des caractéristiques communes identifiables : on a plus souvent affaire à des hommes (61\% contre $47 \%$ dans l'ensemble de la population), non diplômés ( $24 \%$ des personnes de ce groupe sont non diplômées contre $14 \%$ de l'ensemble de la population) et ouvriers (30\% contre $12 \%$ ). À l'exception de ce type qui se caractérise avant tout par un rejet du périmètre classique, on trouve dans les trois autres types des personnes de tous âges, de toutes professions, de tous niveaux d'instruction, sans que domine un groupe social particulier. Néanmoins, le niveau de diplôme exerce une influence sur le degré d'extension du périmètre: les personnes diplômées de l'enseignement supérieur se distinguent ainsi par une acception plus extensive de la culture. Pour elles, le taux de réponses «fait partie de la culture dans tous les cas » est systématiquement supérieur à la moyenne pour toutes les activités classiques comme « aller au théâtre » (75\% contre $62 \%)$, et pour toutes les activités susceptibles d'être envisagées comme artistiques (le cirque, la mode, le design, le rap, le graffiti). Les personnes diplômées de l'enseignement supérieur se caractérisent aussi par le rejet des activités de loisir non artistiques comme la chasse, le sport, le jardinage ou encore la cuisine qu'elles considèrent moins souvent comme culturelles (graphique 6). 
Graphique 6 - Appartenance de 27 domaines au périmètre de la culture pour l'ensemble de la population et pour les diplômés du supérieur

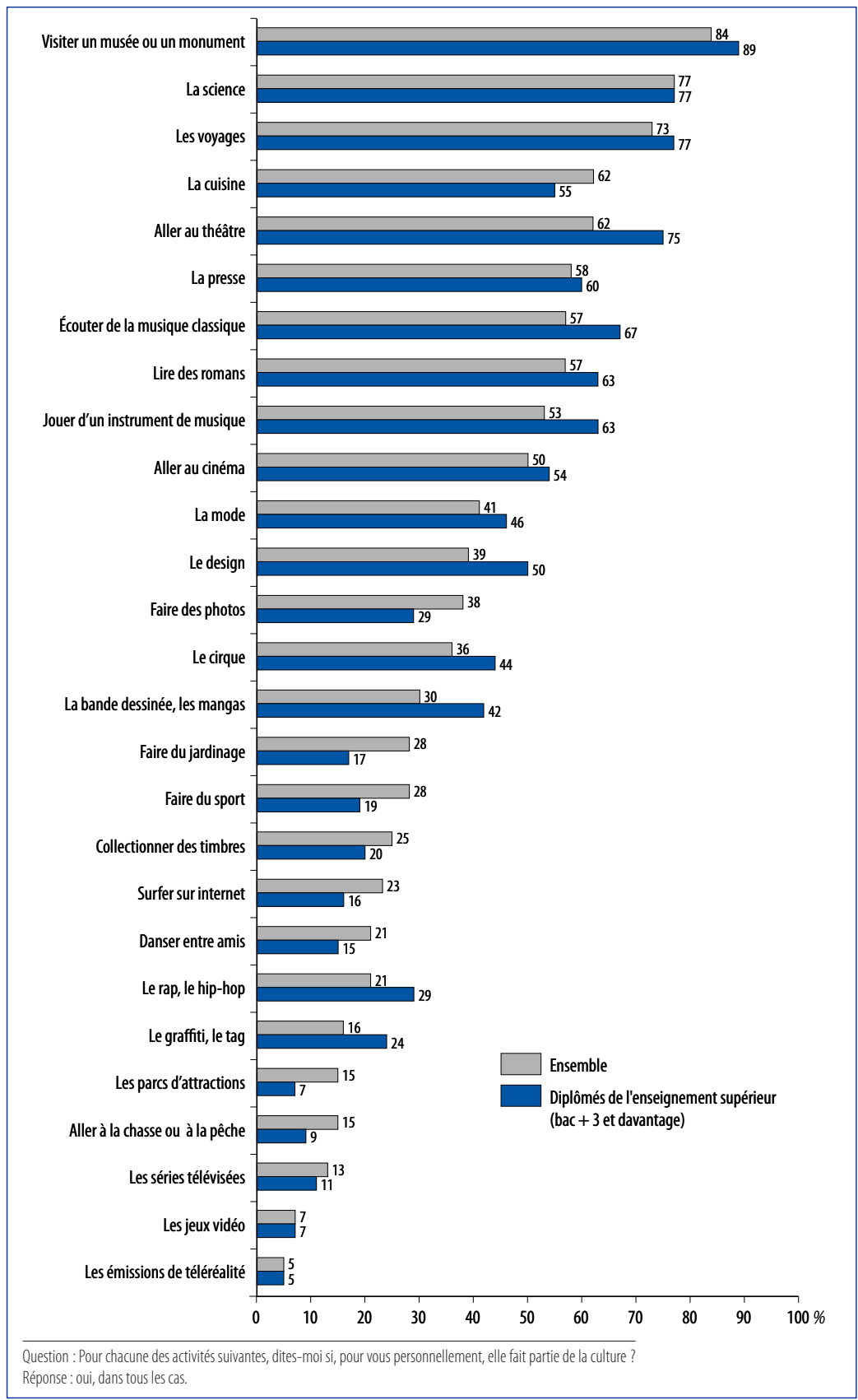




\section{Tout est potentiellement culture, sous condition}

Si les plus diplômés sont plus souvent ceux qui ont une conception du champ culturel tendant à ignorer l'ancienne distinction entre arts majeurs et arts mineurs, ils ont néanmoins une définition qui reste globalement centrée sur les arts. Si l'on met à part les émissions de téléréalité, exclues du champ culturel par une majorité de personnes de toutes conditions, toutes les autres pratiques, y compris les moins artistiques, sont considérées par les plus diplômés comme potentiellement culturelles. Le phénomène est très net pour les bandes dessinées (pour $44 \%$ des diplômés du supérieur, la réponse est conditionnelle), pour la photo (61\%), les séries télévisées (51\%), les graffitis (52\%), mais non moins remarquable pour « danser entre amis » (54\% de «ça dépend des cas »), collectionner des timbres (49\%) ou surfer sur internet (58\%).

On formule donc l'hypothèse que s'est imposée, probablement en se diffusant depuis les plus diplômés jusqu'aux personnes faiblement diplômées, une conception de la culture, ouverte, libérale, éclectique, tolérante, susceptible d'absorber toute activité faisant sens, et de dépasser une vision étroite, scolaire, intimidante de la culture. Dépasser mais non pas effacer : l'extension potentiellement sans limite du périmètre de la culture sauvegarde un cœur - la « culture cultivée », autour du livre, des arts, du patrimoine et des savoirs - tout en permettant de valoriser des modes de vie, des loisirs et des pratiques mettant en œuvre des savoirs et des savoir-faire (comme le sport et le jardinage) plus populaires.

\section{Âge, sexe et lieu de résidence sont des critères moins déterminants que pour la participation culturelle}

Les 15-24 ans se distinguent des autres générations par leur plus grande propension à inclure sans condition dans la culture des modes d'expression et des formes de culture médiatiques (graphique 7) : le graffiti et le tag, le rap et le hip-hop, les séries télévisées, les jeux vidéo, la presse, les bandes dessinées; et, parallèlement, par une plus faible propension que la moyenne à considérer certaines pratiques en amateur comme culturelles: ainsi en va-t-il du fait de jouer d'un instrument de musique, de faire des photos, de collectionner des timbres, de danser entre amis, ou encore de la cuisine et du cirque. Les plus âgés, à l'inverse, sont plus nombreux à inclure dans la culture des pratiques classiques: lire des romans (62\%), jouer d'un instrument de musique $(58 \%)$ mais aussi la science ( $80 \%)$, la cuisine $(67 \%)$, le jardinage $(44 \%)$ et surtout le cirque (44\%).

Les non-diplômés incluent moins fréquemment que les autres dans le périmètre culturel la visite des musées et monuments (77\%), la lecture de romans (50\%), et davantage le fait de faire du sport (37\%), ou de danser entre amis ( $27 \%$ ) et les parcs d'attractions (24\%). En revanche, ils sont nettement moins nombreux à y inclure le graffiti (5\%) et le rap (12\%).

Les personnes résidant dans l'agglomération parisienne se distinguent par leur plus grande propension à inclure dans la culture les formes d'expression historiquement les plus récentes telles que le graffiti ( $26 \%$ ) ou la bande dessinée ( $37 \%$ ) ainsi que la mode (46\%) et le design (45\%). La structure démographique de l'agglomération parisienne, où la part des diplômés du supérieur est plus élevée qu'ailleurs, explique largement que les scores des Parisiens soient, sur ces items, très voisins de ceux des plus diplômés.

Enfin, il faut souligner quelques différences entre les réponses des hommes et des femmes, à propos des voyages, de la presse, de la lecture de romans, de la fréquentation des cinémas et du théâtre, de la musique classique de la pratique photogra- 
Graphique 7 - Appartenance de quelques domaines au périmètre de la culture pour l'ensemble de la population et pour les 15-24 ans

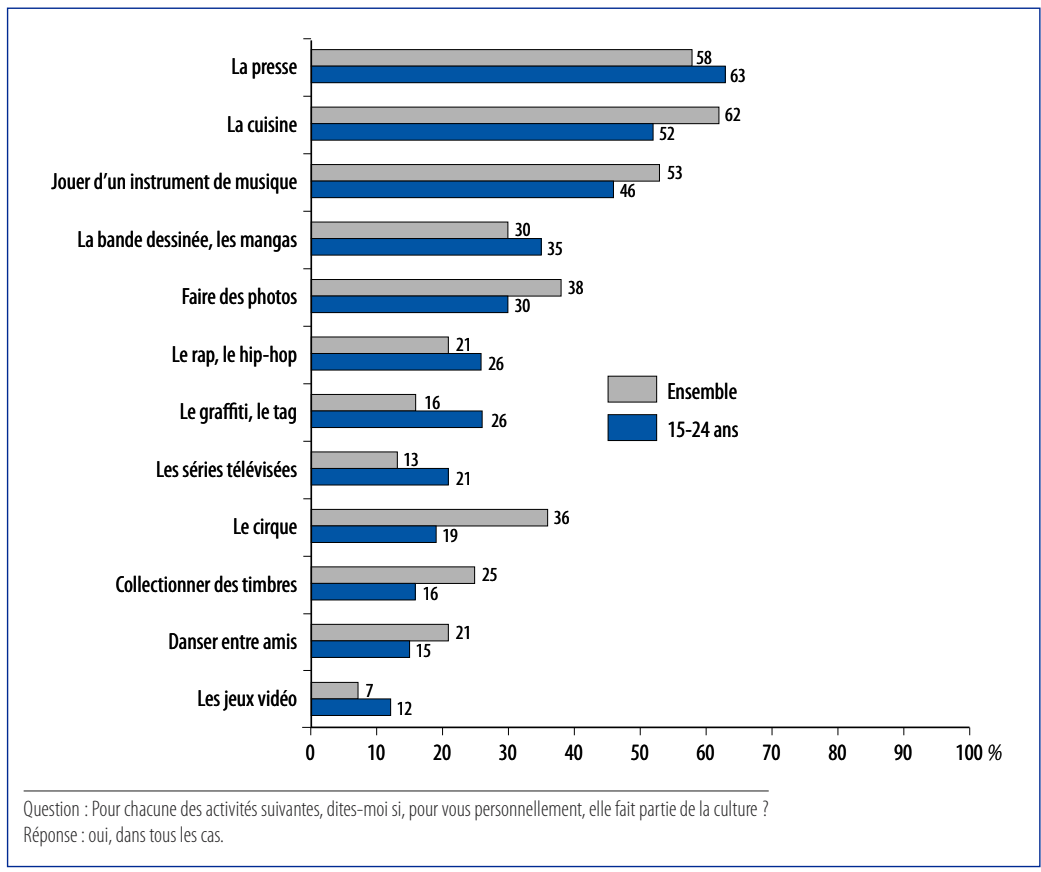

Source : Crédoc/DEPS, Ministère de la Culture et de la Communication, 2016

phique (graphique 8). Les femmes semblent enclines à considérer comme culturels un plus grand nombre de contenus et d'activités.

Si ces écarts signalent des tendances, ils ne permettent pas pour autant de conclure à une détermination sociodémographique des opinions. L'ensemble dessine bien une représentation commune de la culture qui traverse les groupes sociaux: tout est potentiellement culturel. On ne saurait néanmoins oublier l'existence d'une conception réfractaire à cette représentation partagée. 
Graphique 8 - Appartenance des 27 domaines au périmètre de la culture pour l'ensemble de la population selon le sexe

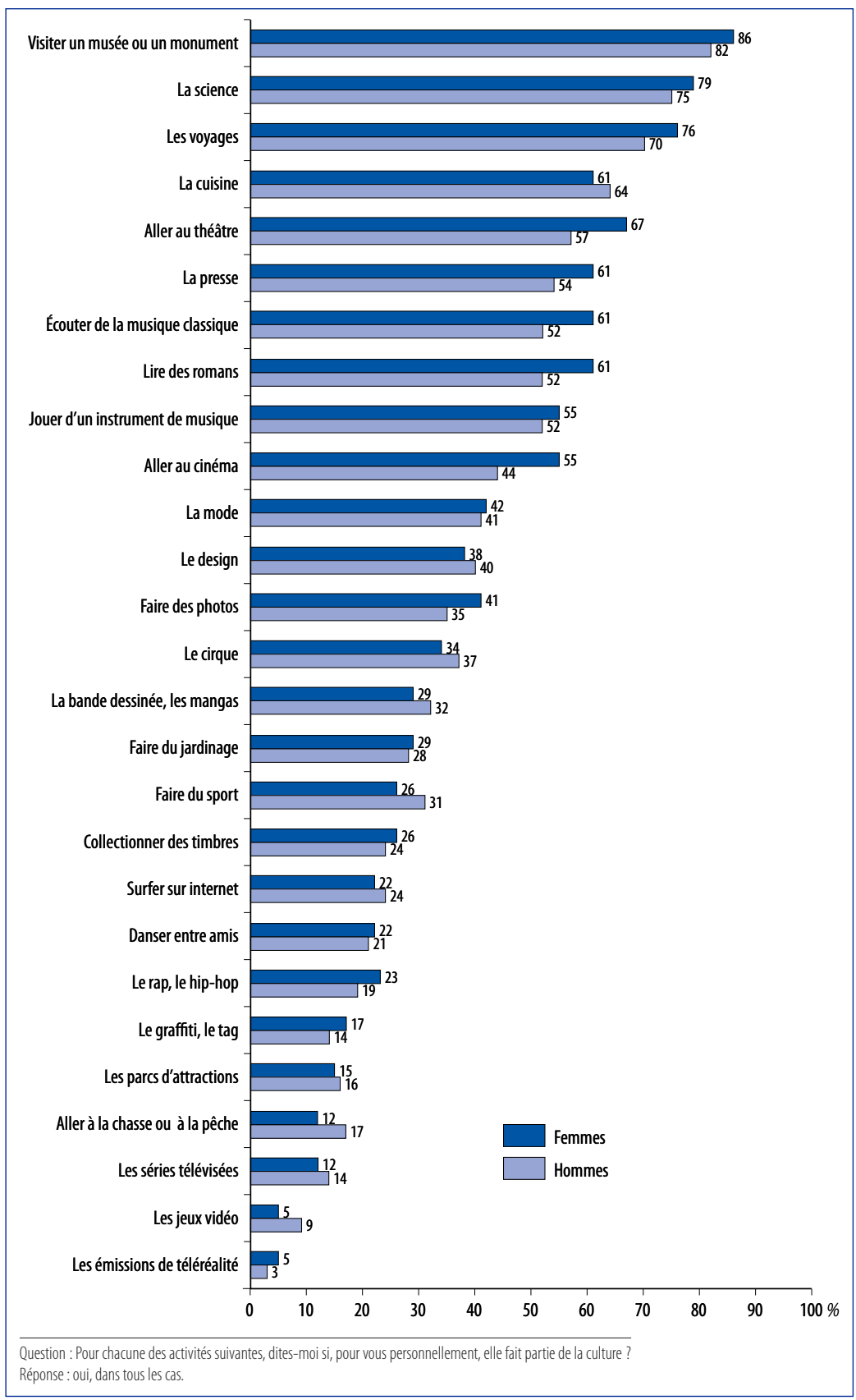




\section{Éléments de méthodologie}

Une enquête par sondage a été conduite en 2015 auprès d'un échantillon représentatif des Français âgés de 15 ans et plus, sur leurs représentations de la culture et les valeurs qu'ils y associent. Elle a été complétée par une enquête qualitative : 30 personnes ayant répondu à l'enquête par sondage ont été recontactées pour un entretien en tête-à-tête.

L'enquête, par sondage a été réalisée en face-à-face, en mode capl (Computer Assisted Personal Interview) avec le logiciel Converso, par les enquêteurs de la société IsL. Le terrain s'est déroulé du 9 avril au 18 mai 2015. En amont du terrain, un questionnaire pilote avait été réalisé au mois de mars auprès de 21 personnes, afin de tester et de valider le questionnaire définitif. Sa durée moyenne était proche de 40 minutes.

Le plan de sondage a été construit selon une matrice grandes régions (9 ZEAT) $\mathrm{x}$ habitat (5 catégories d'agglomération) et l'échantillon a respecté les quotas suivants :

- sexe;

- âge en 6 modalités (15-17 ans ; 18-24 ans, 25-34 ans, 35-49 ans, 50-64 ans, 65 ans et plus);

- PCS en 8 modalités (agriculteurs ; artisans ; cadres et professions libérales; professions intermédiaires ; employés; ouvriers; retraités; autres inactifs);

-habitat en 5 modalités (commune rurale; unité urbaine de moins de 20000 habitants; unité urbaine de 20000 à 100000 habitants, unité urbaine de plus de 100000 habitants, unité urbaine de Paris) ;

-ZEAT en 9 modalités (région parisienne, Bassin parisien est, Bassin parisien ouest, Nord, Est, Ouest, Sud-Ouest, Sud-Est et Méditerranée).

125 enquêteurs professionnels sont intervenus dans les départements des 9 régions ZEAT regroupées (339 communes), interrogeant 1515 personnes au total.

Le fichier final a été apuré et redressé; les résultats sont représentatifs de la population de 15 ans et plus résidant en France métropolitaine.

Un certain nombre de questions se sont volontairement appuyées sur des formulations ayant pu être utilisées dans d'autres enquêtes, à des fins de comparaison et contextualisation: enquête sur les pratiques culturelles du ministère de la Culture et de la Communication, menée à cinq reprises entre 1973 et 2008, enquête de la Commission européenne de 2007 portant sur les pratiques et représentations culturelles, enquête Conditions de vie et aspirations du Crédoc.

Les deux enquêtes, quantitatives par sondage et qualitatives par entretiens, ont été coordonnées par le Crédoc, sous la direction de Sandra Hoibian et Patricia Croutte. 


\section{Abstract}

\section{Representations of Culture in the French Population}

To what does the term "culture" refer in the French imagination, what spontaneous ideas are associated with it and with which registers are they associated? To find out, and as part of the latest 10-yearly survey into cultural practices in France (which has been carried out by the Ministry of Culture and Communication since 1970), the Department for Studies, Forward Planning and Statistics has carried out a survey of the forms and values associated with culture based on a sample of 1500 individuals representative of the French population as a whole. Spontaneous mention of words and expressions to refer to culture may be grouped, according to semantic proximity, into 28 registers. The first of these, cited by $41 \%$ of French people, refers to learning and knowledge, the second to literature and reading and the third to music and dance. Whilst there may be an observable consensus that cultural heritage and the arts, as well as travel, science and cuisine form part of culture in all cases, there are also fairly clearly delineated areas of exclusion, whereby reality TV and television series, video games and theme parks are seen as falling outside of the cultural sphere.

Four major notional areas of culture emerge from this: cultural liberalism (everything is cultural), critical eclecticism (everything is potentially cultural, according to certain criteria), the conservative view (the cultural sphere is not extensible) and the anti-establishment view (real culture is elsewhere).

Whilst young people (those aged 15-24) more readily include media-based forms of expression and culture in their definition, and women include a greater range of content and activities than men, overall there appears to be a lower influence of the variables which have historically determined cultural participation, in particular social background. It seems very much as though there is a fairly broad and firmly-established common view of culture which crosses all social classes.

Directeur de la publication : Loup Wolff, chef du Département des études, de la prospection et des statistiques Responsable de la publication : Edwige Millery

\section{Retrouvez l'ensemble des publications du DEPS : http://www.culturecommunication.gouv.fr/Etudes-et-statistiques http://www.cairn.info/editeur.php?iD_EDITEUR=DEPS http://www.books.openedition.org/deps}

Le DEPS n'assurant pas de diffusion physique de ses collections de synthèse, nous vous proposons de vous informer régulièrement des parutions par message électronique.

Pour ce faire, merci de bien vouloir nous communiquer votre courriel à l'adresse contact.deps@culture.gouv.fr 
可

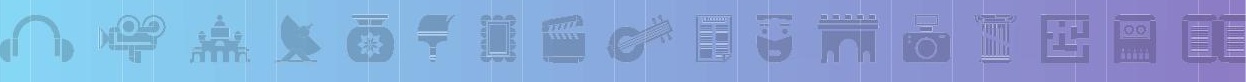

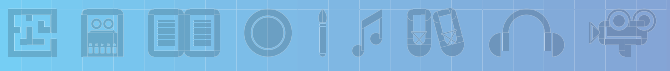

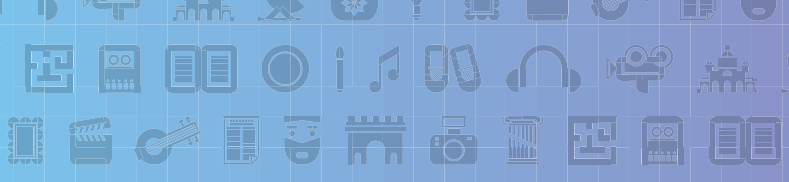

กำ

Que recouvre le terme de «culture » dans l'esprit des Français, quelles sont les représentations spontanées qui lui sont associées et à quels registres renvoient-elles ? Pour le savoir, et dans la perspective de la reconduite de l'enquête décennale sur les pratiques culturelles des Français réalisée depuis I970 par le ministère de la Culture et de la Communication, le Département des études, de la prospective et des statistiques a mené, auprès d'un échantillon de I 500 personnes représentatives de la population française, une étude sur les représentations et les valeurs associées à la culture.

Les évocations spontanées de mots et expressions pour référer à la culture peuvent être regroupées, selon leur proximité sémantique, en 28 registres. Le premier d'entre eux, mobilisé par 4I \% des Français, fait référence au savoir et à la connaissance, le deuxième à la littérature et à la lecture et le troisième à la musique et à la danse. Si l'on observe un consensus autour du patrimoine et des arts, mais aussi des voyages, de la science et de la cuisine comme faisant partie de la culture dans tous les cas, des lignes communes de rejet se dessinent également, excluant du champ culturel les émissions de télé-réalité et les séries télévisées, les jeux vidéo ou les parcs d'attraction.

Quatre grands types de conception de la culture se dégagent : le libéralisme culturel (tout est culturel), l'éclectisme critique (tout est potentiellement culturel, selon certains critères), le classicisme (le champ culturel n'est pas extensible) et l'attitude contestataire (la vraie culture est ailleurs).

Si les jeunes (15-24 ans) incluent volontiers dans la culture des modes d'expression et des formes de culture médiatique, et les femmes un plus grand nombre de contenus et d'activités que les hommes, on observe globalement une faible influence des variables qui déterminent historiquement la participation culturelle, en particulier l'origine sociale. Tout se passe comme si une représentation commune de la culture assez extensive s'était imposée et traversait tous les groupes sociaux. 